\title{
A previously unidentified activity of yeast and mouse RNA:pseudouridine synthases 1 (Pus1p) on tRNAs
}

\author{
ISABELLE BEHM-ANSMANT, ${ }^{1}$ SÉVERINE MASSENET, ${ }^{1}$ FRANÇOISE IMMEL, ${ }^{1}$ JEFFREY R. PATTON, ${ }^{2}$ \\ YURI MOTORIN, ${ }^{1}$ and CHRISTIANE BRANLANT ${ }^{\mathbf{}}$ \\ ${ }^{1}$ Laboratoire de Maturation des ARN et Enzymologie Moléculaire, UMR 7567 CNRS-UHP, Nancy I, Faculté des Sciences, BP 239 , 54506 \\ Vandoeuvre-les-Nancy Cedex, France \\ ${ }^{2}$ Department of Pathology and Microbiology, School of Medicine, University of South Carolina, Columbia, South Carolina 29208, USA
}

\begin{abstract}
Mouse pseudouridine synthase 1 (mPus1p) was the first vertebrate RNA:pseudouridine synthase that was cloned and characterized biochemically. The mPus1p was previously found to catalyze $\Psi$ formation at positions $27,28,34$, and 36 in in vitro produced yeast and human tRNAs. On the other hand, the homologous Saccharomyces cerevisiae scPus1p protein was shown to modify seven uridine residues in tRNAs $(26,27,28,34,36,65$, and 67) and U44 in U2 snRNA. In this work, we expressed mPus1p in yeast cells lacking scPus1p and studied modification of U2 snRNA and several yeast tRNAs. Our data showed that, in these in vivo conditions, the mouse enzyme efficiently modifies yeast U2 snRNA at position 44 and tRNAs at positions 27, 28, 34, and 36. However, a tRNA: $\Psi 26$-synthase activity of mPus1p was not observed. Furthermore, we found that both scPus1p and mPus1p, in vivo and in vitro, have a previously unidentified activity at position 1 in cytoplasmic tRNA $^{\text {Arg }}$ (ACG). This modification can take place in mature tRNA, as well as in pre-tRNAs with $5^{\prime}$ and/or $3^{\prime}$ extensions. Thus, we identified the protein carrying one of the last missing yeast tRNA: $\Psi$ synthase activities. In addition, our results reveal an additional activity of mPus1p at position 30 in tRNA that scPus1p does not possess.
\end{abstract}

Keywords: pseudouridine; scPus1p; mPus1p; tRNA; U2 snRNA

\section{INTRODUCTION}

Pseudouridine $(\Psi)$, is one of the two most abundant modified nucleotides found in stable RNA species, including tRNAs (Bjork et al. 1987), rRNAs (for review, see Ofengand and Fournier 1998), and UsnRNAs (Massenet et al. 1999; for review, see Massenet et al. 1998). Pseudouridine residues in RNAs are formed post-transcriptionally by a group of enzymes called RNA: $\Psi$-synthases (Kammen et al. 1988; Koonin 1996). The isomerization reaction requires no cofactor and no energy source (Kammen et al. 1988).

On the basis of sequence comparisons, four distinct RNA: $\Psi$-synthase families (TruA, TruB, RluA, and RsuA) were defined (Gustafsson et al. 1996; Koonin 1996) and a fifth family (TruD) was recently discovered (BehmAnsmant et al. 2003; Kaya and Ofengand 2003; Ma et al. 2003). RNA: $\Psi$-synthases can function alone, by direct

Reprint requests to: Yuri Motorin, Laboratoire Maturation des ARN et Enzymologie Moléculaire, UMR 7567 CNRS-UHP Nancy I, Faculté des Sciences, BP 239, 54506 Vandoeuvre-les-Nancy Cedex, France; e-mail: iouri.motorine@maem.uhp-nancy.fr; fax: 33.3.83.68.43.07.

Article published online ahead of print. Article and publication date are at http://www.rnajournal.org/cgi/doi/10.1261/rna.100806. interaction with their RNA substrates, or after incorporation into ribonucleoprotein complexes (RNPs) that contain a guide RNA. The guide RNAs ensure the specific recognition of the substrate. In vertebrates, scaRNAs located in Cajal bodies are expected to guide $\Psi$ formation in U1, U2, U4, and U5 snRNAs (Ganot et al. 1999; Jady and Kiss 2001; Darzacq et al. 2002; Zhao et al. 2002; Vitali et al. 2003; Kiss et al. 2004). The RNA-guided RNA: $\Psi$-synthases (dyskerin/ Cbf5) belong to the TruB family.

Although Saccharomyces cerevisiae RNA: $\Psi$-synthases have been extensively studied (for reviews, see Ansmant and Motorin 2001; Ofengand 2002), two S. cerevisiae tRNA:pseudouridine synthase activities acting at position 1 in the cytoplasmic tRNA ${ }^{\text {Arg }}$ (ACG) and tRNA ${ }^{\text {Lys }}$ (UUU) and at position 72 in the mitochondrial tRNA ${ }^{\mathrm{Met}}(\mathrm{CAU})$ (see Fig. 1C,E) remain to be identified (Behm-Ansmant et al. 2004). In addition, only a limited number of RNA: $\Psi$ synthases have been studied in Eukarya: (1) the mouse Pus3p enzyme specific for positions 38 and 39 in tRNAs (Chen and Patton 2000) and (2) the homologs of the S. cerevisiae Pus1p enzyme (scPus1p) from Schizosaccharomyces pombe (spPus1p) (Hellmuth et al. 2000), Caenorhabditis elegans (cePus1p) (Patton and Padgett 2003), and 
A.

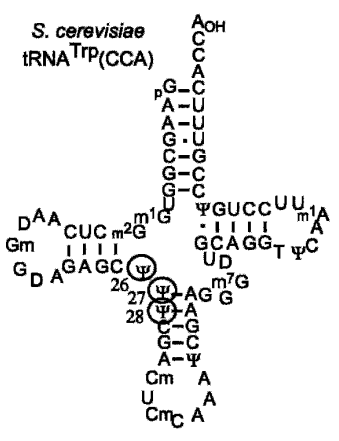

B.
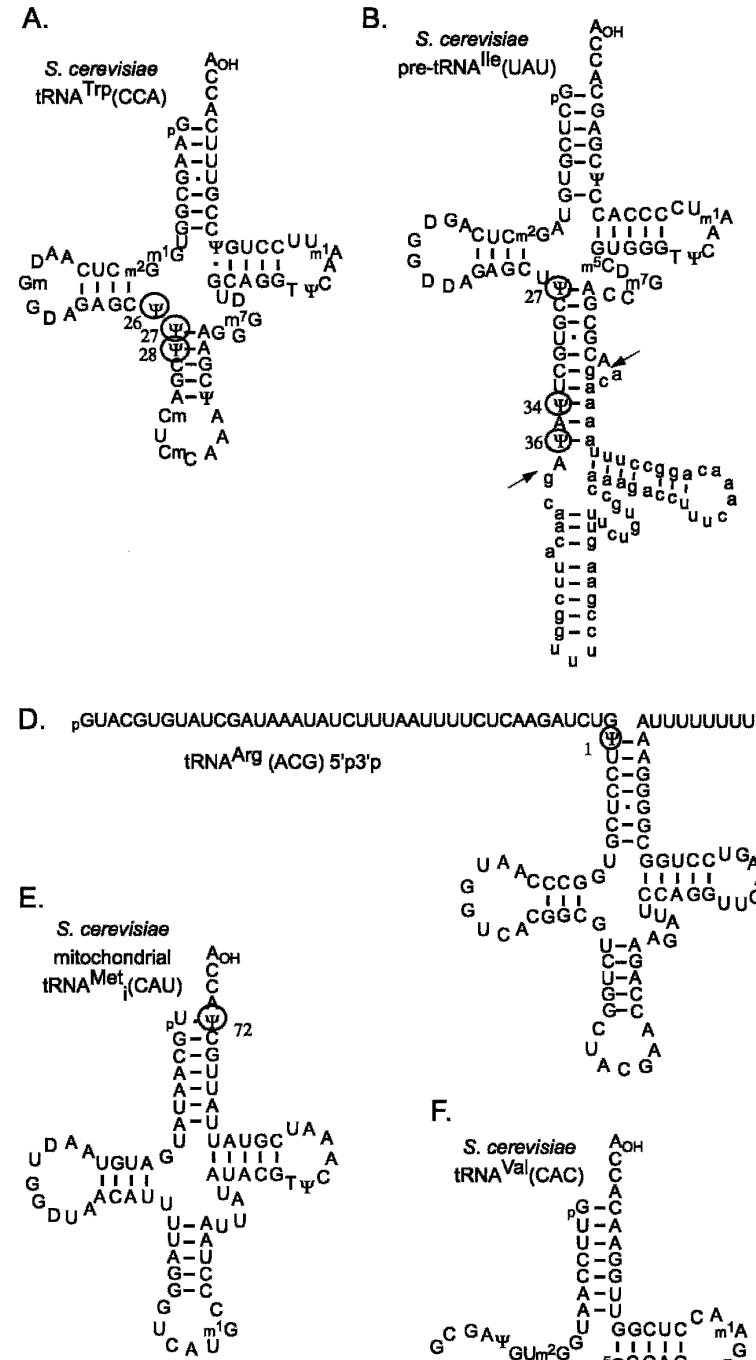

F.

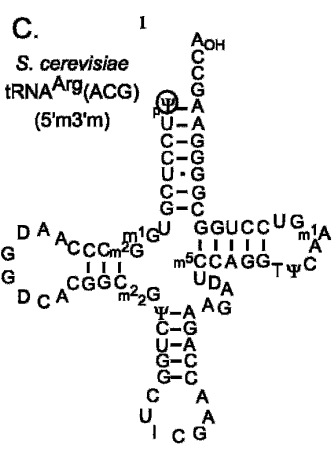

G.

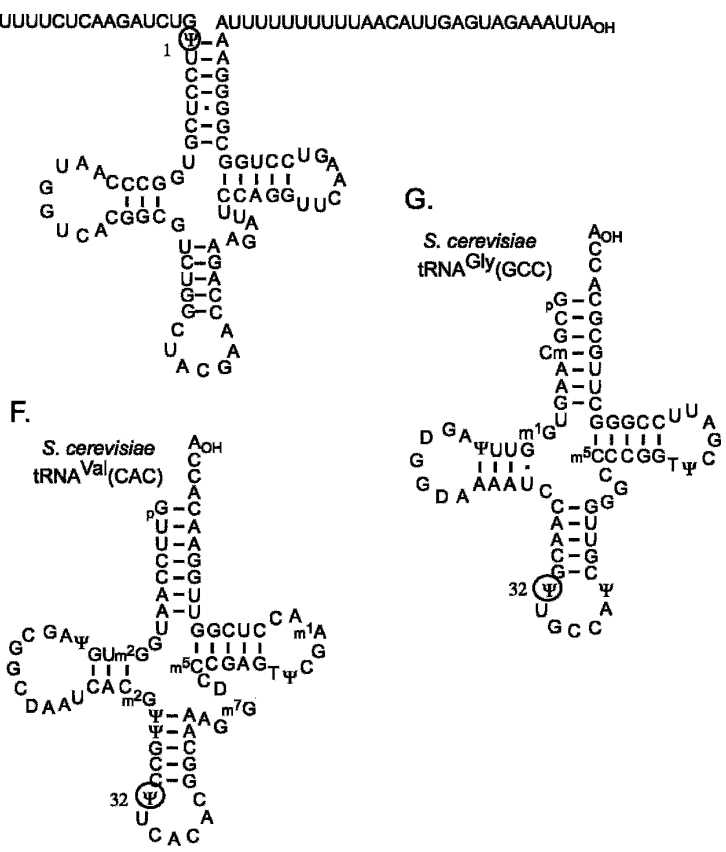

FIGURE 1. Sequences and secondary structures of the $S$. cerevisiae tRNA substrates used in this work. The various panels represent, respectively, the $\operatorname{tRNA}^{\operatorname{Trp}}(\mathrm{CCA})(A)$, the pretRNA $^{\mathrm{Ile}}(\mathrm{UAU})(B)$, the mature tRNA ${ }^{\mathrm{Arg}}(\mathrm{ACG})(C)$, the $5^{\prime} \mathrm{p} 3^{\prime} \mathrm{p}$ tRNA ${ }^{\mathrm{Arg}}(\mathrm{ACG})$ with $5^{\prime}$ and $3^{\prime}$ extensions mimicking a tRNA precursor $(D)$, mitochondrial tRNA ${ }_{i}^{\text {Met }}(\mathrm{CAU})(E)$, tRNA $^{\text {Val }}(\mathrm{CAC})(F)$, and tRNA ${ }^{\text {Gly }}(\mathrm{GCC})(G)$. All tRNAs (except tRNA ${ }^{\text {Arg }}(\mathrm{ACG})$ precursor) are drawn with all their identified post-transcriptional modifications (tRNA database; Sprinzl et al. 1998; see, also, http://www.uni-bayreuth.de/departments/biochemie/sprinzl/trna/). The intronic sequence in pre-tRNA ${ }^{\text {Ile }}$ is shown in small characters and small arrows indicate the exon-intron borders. The $\Psi$ residues studied during this work are circled.

mouse (mPuslp) (Chen and Patton 1999). The Puslp enzymes have a broad RNA recognition specificity. In yeast, scPuslp was shown to modify seven distinct positions in cytoplasmic tRNAs $(26,27,28,34,36,65$, and 67) (Simos et al. 1996; Motorin et al. 1998; Behm-Ansmant et al. 2003) and at position 44 in U2 snRNA (Massenet et al. 1999). The mPuslp specificity was partially characterized by in vitro experiments using synthetic yeast tRNA transcripts and a human pre-tRNA ${ }^{\text {Ser }}$ transcript as the substrates (Chen and Patton 1999). These in vitro experiments showed that, like scPuslp, mPuslp catalyzes $\Psi$ formation at positions 27, 28, 34, and 36 in tRNAs (Chen and Patton 1999).

The interest to complete the analysis of the vertebrate Puslp specificity was recently strengthened by two important findings. One observation arose from the study of patients suffering from mitochondrial myopathy and sideroblastic anemia (MLASA). Indeed, this rare autosomal recessive disorder of oxidative phosphorylation and iron metabolism was found to be a consequence of the inactivation of the Pus1p activity by substitution of a highly conserved R116 residue in human Pus1p (hPuslp) with a W116 residue (Bykhovskaya et al. 2004; Zeharia et al. 2005). The absence of tRNA modification at positions 27 and 28 in patients with MLASA was demonstrated (Patton et al. 2005). The second recent important finding was the unexpected discovery of the mPuslp coactivator activity on class I and class II nuclear receptors (NR) (Zhao et al. 2004). Coactivation of the mouse retinoic acid receptor $\gamma(\mathrm{mRAR} \gamma)$ requires the formation of a triple interaction between mPuslp, the steroid receptor activator (SRA) RNA, and a mRAR $\gamma$ receptor. Furthermore, the mPuslp RNA: $\Psi$-synthase activity is needed for activation. Accordingly, in vitro experiments demonstrated that mPuslp catalyzes $\Psi$ formation in the SRA RNA (Zhao et al. 2004). Thus, mPuslp seems to act on more than one type of RNA substrate as is the case for scPuslp.

To complete the study of the mPus1p specificity, we took advantage of the existence of a $S$. cerevisiae strain lacking scPuslp expression ( $\Delta$ pus1 cells), which was previously used to study the scPus1p specificity in vivo (Motorin et al. 1998; Massenet et al. 1999). The mPuslp activity was tested in $\Delta p u s 1$ cells and compared with in vitro results. Modification of both tRNAs and U2 snRNA was tested and we investigated whether scPuslp and mPuslp exhibit one or both of the yet unidentified yeast tRNA: $\Psi$-synthase activities, namely, pseudouridylation at position 1 in the cytoplasmic tRNA $^{\text {Arg }}$ (ACG) and tRNA ${ }^{\text {Lys }}$ (UUU) (Madison and Boguslawski 1974; Weissenbach et al. 1975) and pseudouridylation 
at position 72 in the mitochondrial $\mathrm{tRNA}^{\mathrm{Met}}{ }_{\mathrm{i}}(\mathrm{CAU})$ (Canaday et al. 1980).

Here we describe an extensive comparison of the mPuslp and scPuslp activities in vivo and in vitro. Our data demonstrate that mPuslp modifies position 44 in yeast U2 snRNA and that both mPuslp and scPuslp modify the cytoplasmic tRNA ${ }^{\mathrm{Arg}}(\mathrm{ACG})$ at position 1 .

\section{RESULTS}

\section{In yeast, mPus1p modifies U2 snRNA at position 44 and tRNAs at positions 26, 27, 28, 34, and 36}

To test whether mPuslp can functionally replace its yeast homolog, we expressed mPus1p in a S. cerevisiae strain with a PUS1 ORF disruption ( $\Delta p u s 1$ ) (see Materials and Methods). To accomplish this, we cloned the wild-type and a mutated version of the mPUS1 ORF in the p416GalS yeast expression plasmid, downstream from the GalS promoter. In the variant mPuslp, the essential Asp112 residue from the conserved ARTD motif of the active site was substituted with an Ala residue (D112A). The resulting recombinant plasmids were used for complementation assays in the $\Delta p u s 1$ strain.

U2 snRNA pseudouridine residues were identified by the CMCT/RT approach as previously described, using total RNA from extracts as templates (Massenet et al. 1999). As expected, only residue $\Psi 44$ disappeared in the $\Delta p u s 1$ strain (Fig. 2B, lanes 5,6), and the modification was recovered upon expression of the wild-type mPuslp (Fig. 2B, lanes 7,8 ), but not of the $\mathrm{D} 112 \mathrm{~A}$ variant protein (Fig. $2 \mathrm{~B}$, lanes $9,10)$. Analysis of the 110-nt segment at the $5^{\prime}$ extremity of U2 snRNA (Fig. 2A) showed that mPuslp modified only position 44 in this fragment.

To study the in vivo activity of mPuslp at positions 26, 27, and 28 in cytoplasmic tRNAs, we chose the yeast tRNA $^{\text {Trp }}$ (CCA) (Fig. 1A; Keith et al. 1972), which is modified by scPus1p at positions 26, 27, and 28 (Motorin et al. 1998). As expected, no $\Psi$ residue was detected at these three positions in the $\mathrm{tRNA}^{\mathrm{Trp}}$ from the untransformed $\Delta$ pus1 strain (Fig. 3, lanes 7,8). The mPus1p expression predominantly restored $\Psi$ formation at position 27 (Fig. 3, lanes 11,12). Reverse transcription stops were detected at the adjacent $\mathrm{U} 26$ and $\mathrm{U} 28$ residues, but the intensity of the bands was only slightly higher than the one observed at the same positions with the $\Delta p u s 1$ strain (Fig. 3, cf. lanes 7,8 and 11,12).

Mouse Puslp was previously shown to form residues $\Psi 27, \Psi 34$, and $\Psi 36$ in an in vitro transcribed yeast pretRNA $^{\text {Ile }}($ UAU) (Fig. 1B; Chen and Patton 1999). By CMCT/RT analysis of the pre-tRNA ${ }^{\text {Ile }}$ (UAU) extracted from the control $\Delta p u s 1$ strain and the $\Delta p u s 1$ strain expressing mPuslp, we showed that the in vivo expressed mPuslp modifies the pre-tRNA ${ }^{\text {Ile }}(\mathrm{UAU})$ at positions 27 , 34, and 36 (Fig. 4). However, modification by mPuslp at

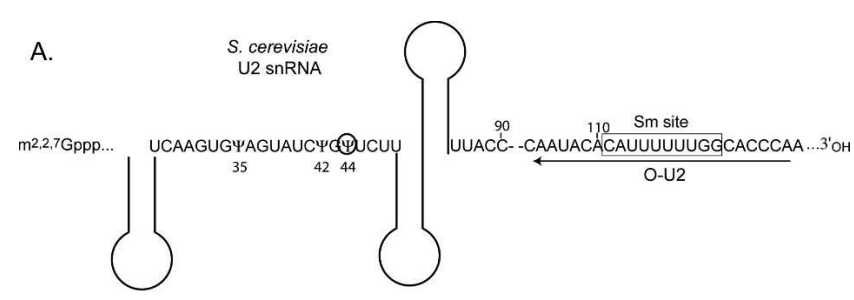

B.

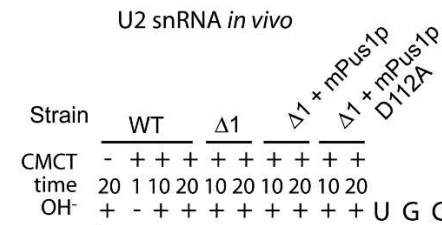

$\mathrm{OH}^{-}+-++++++++\cup \mathrm{UCCA}$

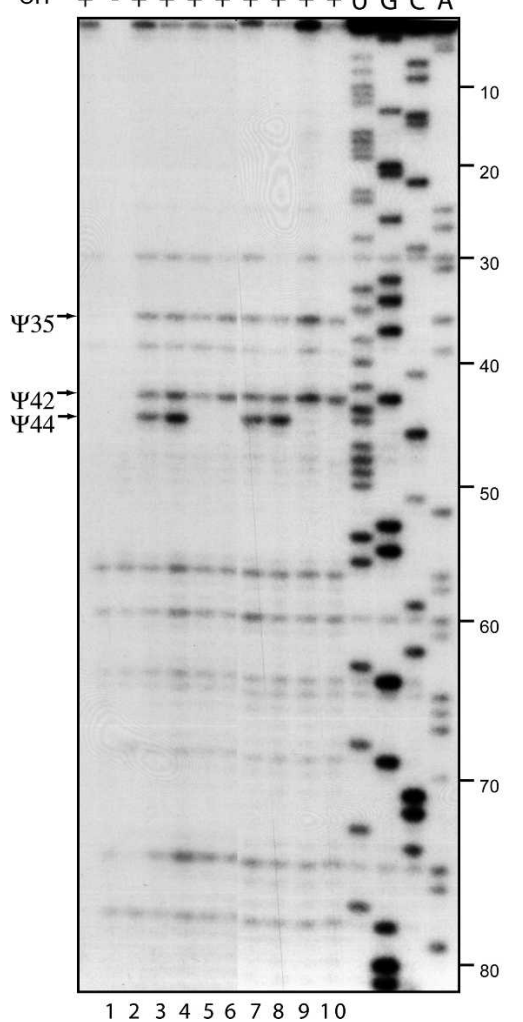

FIGURE 2. The mPuslp enzyme is able to modify yeast U2 snRNA at position 44 in vivo. $(A)$ The $5^{\prime}$-terminal part of U2 snRNA containing three identified $\Psi$ residues (Massenet et al. 1999). The oligonucleotide $(\mathrm{O}-\mathrm{U} 2)$ used for primer extension of $\mathrm{U} 2$ snRNA is indicated by an arrow. $(B)$ Identification of in vivo pseudouridylation of U2 snRNA by CMCT/RT approach. The yeast $S$. cerevisiae $\Delta p u s 1$ strain was transformed with $\mathrm{p} 416 \mathrm{GalS}$ plasmids bearing either the wild-type or the mutated mPUS1 ORF. Total RNAs were extracted from the wild-type, $\Delta$ pus $1(\Delta 1), \Delta p u s 1+$ p416GalSmPUS1D112 $(\Delta 1+$ mPus1p $), \quad$ and $\Delta$ pus $1+$ p416GalsmPUS1D112A $(\Delta 1+$ mPus1p D112A) cells and modified by CMCT, for 1,10 , and $20 \mathrm{~min}$ with $(+)$ or without $(-)$ subsequent alkaline treatment $\left(\mathrm{OH}^{-}\right)$, as previously described (Bakin and Ofengand 1993; Massenet et al. 1999). A control experiment was performed in the absence of CMCT treatment. The pseudouridylated positions were identified by extension of oligonucleotide O-U2 with reverse transcriptase. Lanes $U, G, C$, and $A$ correspond to the sequencing ladders obtained with the same oligonucleotide. The reverse transcription stops, corresponding to residue $\Psi 44$ and to residues $\Psi 35$ and $\Psi 42$, are indicated. 


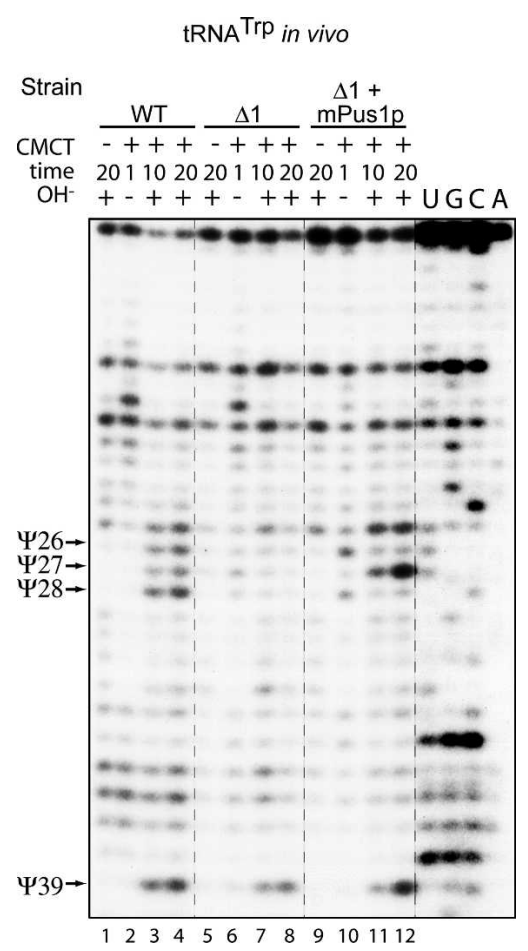

FIGURE 3. Analysis of in vivo mPuslp activity on yeast tRNA ${ }^{\text {Trp }}$. Total RNAs were extracted from the wild-type, $\Delta$ pus $1(\Delta 1)$, and $\Delta$ pus $1+\mathrm{p} 416 \mathrm{GalS}-\mathrm{mPUS1}(\Delta 1+\mathrm{mPus} 1 \mathrm{p})$ cells and were modified by CMCT, for 1,10 , and 20 min with $(+)$ or without $(-)$ subsequent alkaline treatment $\left(\mathrm{OH}^{-}\right)$, in conditions previously described (Massenet et al. 1999). A control experiment was performed in the absence of CMCT treatment. Pseudouridylated positions were identified by extension of oligonucleotide O-tRNA ${ }^{\text {Trp }}$ by reverse transcriptase. Lanes $U, G, C$, and $A$ correspond to the sequencing ladders obtained with the same oligonucleotide. The reverse transcription stops, corresponding to residues $\Psi 26, \Psi 27, \Psi 28$, and $\Psi 39$, are indicated.

position 36 was less efficient than modification by scPuslp (Fig. 4, lanes 3,4 and 7,8). Since the conversion of the pre-tRNA ${ }^{\text {Ile }}$ into mature tRNA $^{\text {Ile }}$ is dependent on the presence of the intron and takes place in the nucleus, $\Psi 34$ and $\Psi 36$ formation by mPuslp in vivo strongly suggests that mPuslp was efficiently transported to the yeast nucleus.

\section{mPus1p may have a tRNA: $\Psi 30$-synthase activity}

Interestingly, the CMCT/RT analysis of the pre-tRNA ${ }^{\text {Ile }}$ (UAU) modified in $\Delta p u s 1$ cells expressing mPus1p revealed an unexpected reverse transcription stop at position 30 (Fig. 4, lanes 7,8). This stop was not detected when the pretRNA $^{\text {Ile }}$ was extracted from wild-type cells or from untransformed $\Delta p u s 1$ cells. The dependence of the detected RT stop on CMCT modification and its resistance to alkaline treatment demonstrate that it corresponds to a $U$ to $\Psi$ conversion. We conclude that mPuslp can modify residue U30 in yeast pre-tRNA ${ }^{\text {Ile }}$ in vivo. This result was confirmed in vitro by incubation of total RNA extracted from the $\Delta p u s 1$ strain, which was lacking the modification at position 30 , with the recombinant mPus1p (data not shown). Interestingly, when the same in vitro experiment was performed with scPuslp, no significant modification was detected at position 30 of the pretRNA $^{\text {Ile }}(\mathrm{UAU})$ (data not shown).

\section{Both scPus1p and mPus1p have a tRNA: $\Psi 1$-synthase activity}

We then tested whether scPuslp and mPuslp may have a tRNA: $\Psi 1$-synthase activity on cytoplasmic tRNA ${ }^{\mathrm{Arg}}(\mathrm{ACG})$ (Fig. 1C). The presence of a $\Psi$ residue at position 1 in tRNAs can easily be detected by nuclease P1 digestion of 5' end-labeled tRNAs since, depending on the nature of residue 1 , a $\left[5^{\prime}-{ }^{32} \mathrm{P}\right] \Psi \mathrm{MP}$ or a $\left[5^{\prime}-{ }^{32} \mathrm{P}\right] \mathrm{UMP}$ will be released. The in vitro transcribed cytoplasmic tRNA ${ }^{\mathrm{Arg}}$ (ACG) was $5^{\prime}$-end labeled using $\left[\gamma-{ }^{32} \mathrm{P}\right] \mathrm{ATP}$ and $\mathrm{T} 4$
A.

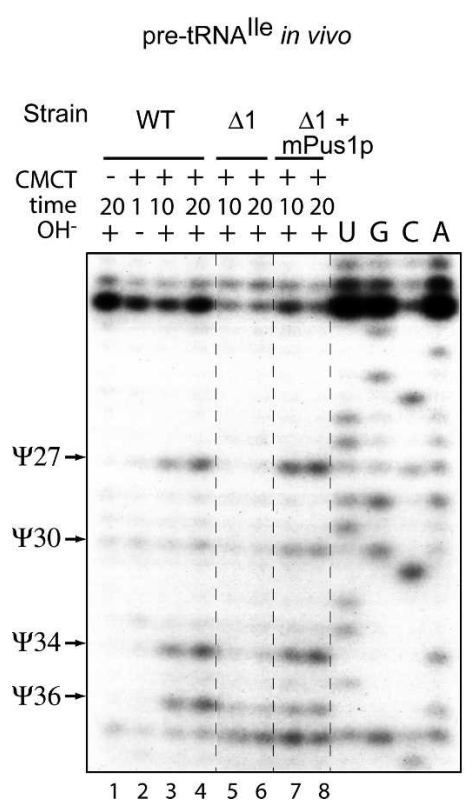

B.

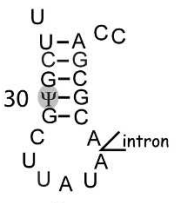

pre-tRNAlle (UAU) yeast

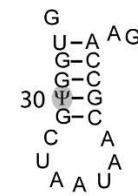

tRNA ${ }^{\text {lle }}(\mathrm{AAU})$ mouse

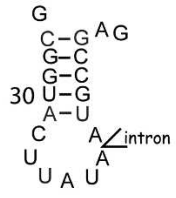

pre-tRNA ${ }^{\text {Ile }}(U A U)$ mouse
FIGURE 4. Analysis of in vivo mPuslp activity on yeast pre-tRNA ${ }^{\text {Ile }}$. Total RNAs were extracted from the wild-type, $\Delta p u s 1(\Delta 1)$, and $\Delta$ pus1 + p416GalS-mPUS1 $(\Delta 1+$ mPuslp $)$ cells and modified by CMCT, for 1,10 , and $20 \mathrm{~min}$ with $(+)$ or without $(-)$ subsequent alkaline treatment $\left(\mathrm{OH}^{-}\right)$, in conditions previously described (Massenet et al. 1999). A control experiment was performed in the absence of CMCT treatment. Pseudouridylated positions were identified by extension of oligonucleotide O-pre-tRNA ${ }^{\text {Ile }}$ with reverse transcriptase. Lanes $U, G, C$, and $A$ correspond to the sequencing ladders obtained with the same oligonucleotide. The reverse transcription stops, corresponding to residues $\Psi 27, \Psi 30, \Psi 34$, and $\Psi 36$, are indicated. $(B)$ Sequence comparison of the yeast pre-tRNA ${ }^{\text {lle }}$ (UAU), mouse tRNA ${ }^{\mathrm{Ile}}(\mathrm{AAU})$, and mouse pre-tRNA ${ }^{\mathrm{Ile}}(\mathrm{UAU})$ anticodon stem-loops. Positions of introns in the pre-tRNAs are indicated. 
polynucleotide kinase and then incubated with a wild-type or $\Delta$ pus 1 cellular extract. After nuclease P1 digestion, the resulting $5^{\prime}$-NMPs were fractionated by $2 \mathrm{D}$-TLC. As shown in Figure $5 \mathrm{~A}, \Psi 1$ formation was detected after incubation with the wild-type extract, but not with the $\Delta p u s 1$ cell extract. These data were further confirmed by analysis of cellular RNA fractions highly enriched in tRNAs (see Materials and Methods), that were prepared from wildtype cells, $\Delta$ pus 1 cells, or $\Delta$ pus 1 cells expressing mPus1p. As above, to test whether the $\operatorname{tRNA}^{\mathrm{Arg}}(\mathrm{ACG})$ and tRNA ${ }^{\mathrm{Lys}}$ (UUU) present in these fractions had a $\Psi$ residue at position 1, RNAs from these fractions were $5^{\prime}$-end labeled and analyzed by nuclease P1 digestion, followed by 2D-TLC. As shown in Figure 5B, only $\left[5^{\prime}-{ }^{32}\right.$ P]UMP was detected in the digestion products of RNAs isolated from the $\Delta$ pus 1 cells, whereas both $\left[5^{\prime}-{ }^{32} \mathrm{P}\right] \Psi \mathrm{MP}$ and $\left[5^{\prime}-{ }^{32} \mathrm{P}\right]$ UMP were observed for RNAs isolated from both the wildtype cells and $\Delta$ pus 1 cells expressing mPus1p. Thus, when

A.

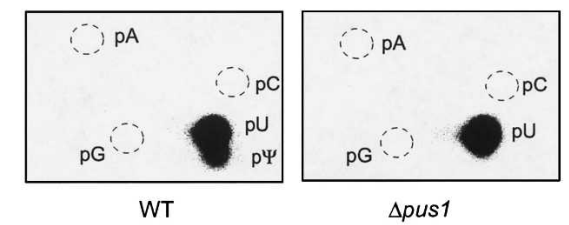

B.

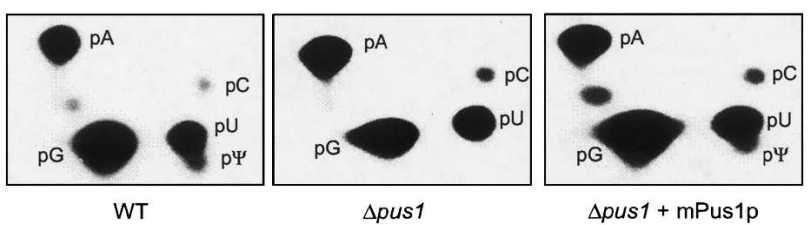

C.

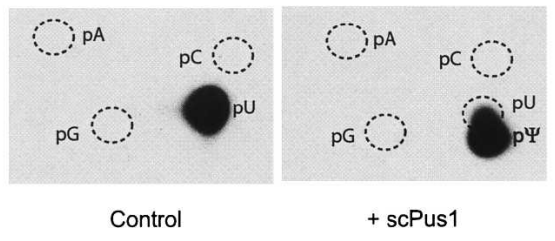

FIGURE 5. Analyses of the tRNA: $\Psi 1$-synthase activity in vitro and in vivo. (A) In vitro transcribed yeast $\mathrm{tRNA}^{\mathrm{Arg}}$ was $5^{\prime}$ labeled with $\left[\gamma^{32} \mathrm{P}\right]$ ATP and incubated with S10 extracts from the wild-type or $\Delta$ pusl cells in conditions described in Materials and Methods. After incubation, the transcripts were digested with nuclease P1 and 5'NMPs were fractionated by 2D-TLC as previously described (Jiang et al. 1997). The autoradiograms of the TLC plates are shown. Positions of the $5^{\prime}$-NMPs (pA, pC, pU, pG, and $\left.\mathrm{p} \Psi\right)$ were identified according to Keith (1995). (B) The tRNA enriched fractions from the wild-type, $\Delta$ pus 1 , and $\Delta$ pus $1+$ p416GalS-mPUS1 $(p)(\Delta 1+$ mPuslp $)$ strains were dephosphorylated and subsequently $5^{\prime}$-end labeled with $\left[\gamma^{-}{ }^{32} \mathrm{P}\right]$ ATP. The identity of the nucleotide at the $5^{\prime}$ extremity of tRNAs was then analyzed by nuclease P1 digestion, followed by 2D-TLC as in A. Panel $(C)\left[5^{\prime}-{ }^{32} \mathrm{P}\right]$-labeled tRNA ${ }^{\text {Arg }}$ transcript incubated (+scPus1p) or not (control) with the recombinant scPuslp was digested with nuclease P1. Positions of nonradioactive nucleotide marquers ( $\mathrm{pA}$, $\mathrm{pC}, \mathrm{pG})$ are indicated by dashed circles. expressed in yeast, both scPuslp and mPuslp have a tRNA: $\Psi 1$-synthase activity.

To further confirm the site of scPuslp activity on $\mathrm{tRNA}^{\mathrm{Arg}}$ (ACG), the in vitro transcribed $\mathrm{tRNA}^{\mathrm{Arg}}$ (ACG) was $5^{\prime}$-end labeled and we studied the identity of its terminal nucleotide after incubation with the recombinant scPuslp. As shown in Figure 5C, residue U1 in tRNA ${ }^{A r g}$ is almost completely transformed into a $\Psi 1$ residue. This clearly demonstrated the tRNA: $\Psi 1$-activity of scPus $1 p$.

Like all other yeast tRNAs, $\mathrm{tRNA}^{\mathrm{Arg}}$ (ACG) and tRNA ${ }^{\text {Lys }}$ (UUU) are transcribed as pre-tRNAs in yeast and it was interesting to know whether scPuslp and mPuslp can act at position 1 (as referred to the mature tRNAs) in the pretRNAs and their maturation intermediates. To answer this question, RNAs that mimic the pre-tRNA ${ }^{\text {Arg }}$ (ACG) transcript, its maturation intermediates, and the mature tRNA were produced by in vitro transcription and then incubated with the recombinant scPus1p and mPus1p enzymes. Since the transcription initiation and termination sites of the $\mathrm{tRNA}^{\mathrm{Arg}}$ (ACG) gene have not been identified, we produced a tRNA ${ }^{\text {Arg }}$ transcript containing a 40-nt-long 5' extension and a 29-nt-long $3^{\prime}$ extension to mimic the authentic transcript (Fig. 1D). This transcript was designated as 5'p3'p tRNA Arg. Typically, pre-tRNA maturation in yeast starts by the elimination of the $5^{\prime}$ extension by RNase P (for review, see Schon 1999). Therefore in order to mimic this partially mature tRNA we also produced a tRNA ${ }^{A r g}$ transcript containing only the $3^{\prime}$ extension $\left(5^{\prime} \mathrm{m} 3^{\prime} \mathrm{p}\right.$ $\left.\mathrm{tRNA}^{\mathrm{Arg}}\right)$. However, in a few cases, as for $\mathrm{tRNA}^{\mathrm{Trp}}$, maturation of yeast tRNA starts by elimination of the $3^{\prime}$ extension (Kufel and Tollervey 2003). Therefore we also produced a tRNA ${ }^{\mathrm{Arg}}$ transcript with only the $5^{\prime}$ extension (5' $3^{\prime} \mathrm{m}$ tRNA ${ }^{\mathrm{Arg}}$ ). In all these transcripts a $\mathrm{U}$ residue was present immediately downstream from the targeted U1 residue, so that $\Psi 1$ formation was tested by the nearest neighbor approach, using transcripts labeled by $\left[\alpha-{ }^{32} \mathrm{P}\right]$ UTP incorporation. Another potential target of Puslp modification in this tRNA (U27) is followed by a C residue, so that its modification could not detected by the nearest neighbor approach. As shown in Figure 6, all the tested transcripts were efficiently modified upon incubation with recombinant mPusp1 or scPusp1 enzymes, and the mole $\Psi$ /mole tRNA ratio was always $\leq 1$, indicating that the only modification detected was that at position 1 . Since several UU dinucleotides were present in transcripts mimicking the precursor tRNA and its maturation intermediates, we used the CMCT/RT approach to show for one of them (the 5'p3'm transcript) that the modification detected by the nearest neighbor approach indeed occurred at position 1. Figure 7 (lanes 5 and 6) demonstrates that this is the case. Within the $90 \mathrm{nt}$ examined in the CMCT/RT analysis, only position 1 was found to be significantly converted into a $\Psi$ residue. These results clearly indicate that both scPus1p and mPus1p can catalyze $\Psi 1$ formation in the 
A.

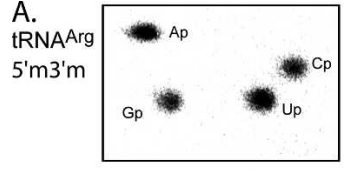

Control

$<0.01$ mole/mole tRNA

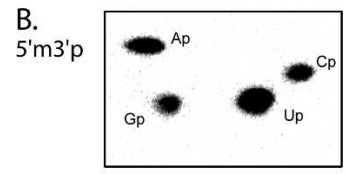

Control $<0.01$ mole/mole tRNA

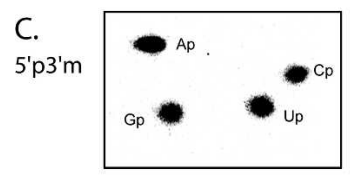

Control $<0.01$ mole/mole tRNA

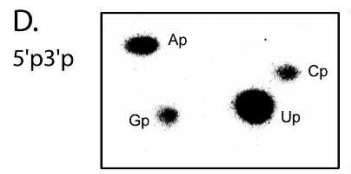

Control

$<0.01$ mole/mole tRNA

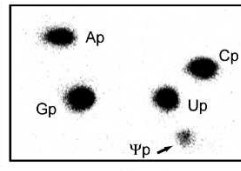

+ scPus1p

$0.66 \mathrm{~mole} / \mathrm{mole}$ tRNA

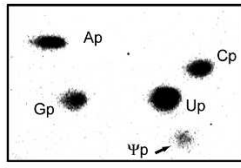

+ scPus1p 0.92 mole/mole tRNA

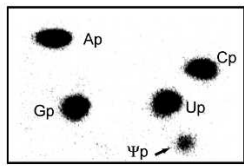

+ scPus1p
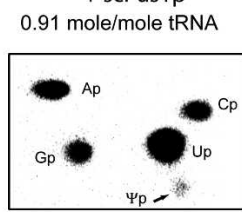

+ scPus1p

$0.79 \mathrm{~mole} / \mathrm{mole}$ tRNA

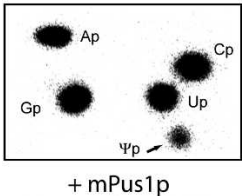

+ mPus1p

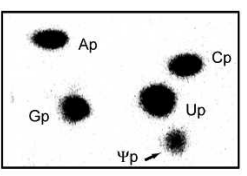

+ mPus $1 p$

0.88 mole/mole tRNA
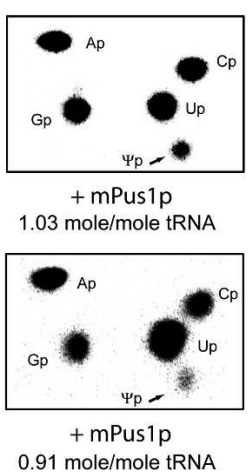

FIGURE 6. Analyses of the in vitro tRNA: $\Psi 1$-synthase activity of recombinant scPuslp and mPuslp enzymes on yeast tRNA ${ }^{\mathrm{Arg}}$ variants. In vitro transcribed RNA substrates, corresponding to yeast mature tRNA ${ }^{\mathrm{Arg}}(A), \mathrm{tRNA}^{\mathrm{Arg}}$ with a $3^{\prime}$ extension $\left(5^{\prime} \mathrm{m} 3^{\prime} \mathrm{p}\right)(B), \mathrm{tRNA}^{\mathrm{Arg}}$ with a $5^{\prime}$ extension $\left(5^{\prime} \mathrm{p}^{\prime} \mathrm{m}\right)(C)$, and tRNA ${ }^{\text {Arg }}$ with both $5^{\prime}$ and $3^{\prime}$ extensions $\left(5^{\prime} \mathrm{p} 3^{\prime} \mathrm{p}\right)(D)$ were labeled by incorporation of $\left[\alpha-{ }^{32} \mathrm{P}\right] \mathrm{UTP}$ and incubated with or without the recombinant $\mathrm{His}_{6}{ }^{-}$ scPuslp (scPuslp) or $\mathrm{His}_{6}-\mathrm{mPuslp}$ (mPuslp) enzyme. After incubation, the transcripts were digested with RNase T2, and 3'-NMPs were fractionated on 2D-TLC. The autoradiograms of the TLC plates are shown. Positions of the $3^{\prime}$-NMPs (Ap, Cp, Up, Gp, and $\Psi \mathrm{p}$ ) were identified according to Keith (1995). Quantification of the formed $\Psi$ residue was done by measuring the radioactivity in each spot with a PhosphoImager, using the ImageQuant software and is indicated below the panel.

mature $\mathrm{tRNA}^{\mathrm{Arg}}$, the pre-tRNA ${ }^{\mathrm{Arg}}$, and its maturation intermediates.

\section{Both scPus1p and mPus1p lack

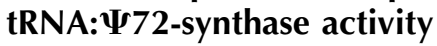

Finally, we tested whether scPuslp and mPuslp may act at position 72 in the mitochondrial tRNA ${ }^{\mathrm{Met}}{ }_{\mathrm{i}}(\mathrm{CAU})$ (Fig. $1 \mathrm{E})$, which is the last position in yeast tRNAs without attributed RNA:pseudouridylation activity. To this end, in vitro transcribed yeast mitochondrial tRNA ${ }_{i}^{\text {Met }}$ was incubated with cell-free extracts from wild-type cells and $\Delta p u s 1$ cells, either with or without the plasmid expressing mPus1p. The data showed that the tRNA: $\Psi 72$-synthase activity was still present in the $\Delta p u s 1$ strain (Table 1). Moreover, neither the recombinant scPuslp nor the recombinant mPus1p were able to modify a yeast mitochondrial tRNA ${ }^{\mathrm{Met}}{ }_{\mathrm{i}}$ transcript at position 72 (Table 1). Thus, it seems unlikely that either scPus1p or mPus1p has a tRNA: $\Psi 72$-synthase activity.

\section{DISCUSSION}

\section{mPus1p has the same activity on yeast U2 snRNA as scPus1p}

Here we demonstrate that, like scPus1p, mPus1p acts at position 44 in yeast $\mathrm{U} 2$ snRNA in vivo. Previous studies on C. elegans showed that the disruption of the cePuslp gene results in the absence of $\Psi 27$ formation in tRNAs, but has no effect on $\Psi 45$ formation in U2 snRNA (the counterpart of $\Psi 44$ in yeast U2 snRNA) (Patton and Padgett 2003). It was thus proposed that this modification may be catalyzed by an RNA-guided enzyme in eukaryotes other than yeasts. However, with respect to human scaRNAs, which are the best studied among vertebrate scaRNAs, only 8 out of $13 \Psi$ residues present in human U2 snRNA can be guided by the presently identified scaRNAs (Vitali et al. 2003; Kiss et al. 2004), and position 43, which is the counterpart of the yeast U2 snRNA position 44, is not one of these. In addition, as previously proposed ( $\mathrm{Ma}$ et al. 2005), one cannot exclude the possible existence of two distinct systems for generation of critical post-transcriptional modifications in UsnRNAs. This may be the case of $\Psi 44$ in U2 snRNA since $\Psi$ formation at this position in yeast is phylogenetically conserved in all studied eukaryal species. In addition, it is found in a segment of U2 snRNA located upstream of the branch site complementary sequence (Fig. 8), which is involved in the binding of several important splicing factors: an SF3b component Cus1p (Wells et al. 1996; Yan et al. 1998), the protein complex of Prp9p, Prp11p, and Prp21p (Wells and Ares 1994), and RNA helicase Prp5p (Wells and Ares 1994; Gozani et al. 1996). Moreover, the modified U2 snRNA segment is involved in formation of Helix III with U6 snRNA (Fig. 8; Sun and Manley 1995).

\section{Comparison of yeast and mouse Pus1p activities on tRNAs}

In the previous study, the recombinant mPuslp enzyme was found to modify residue $\mathrm{U} 32$ at low yield in an in vitro transcribed $S$. cerevisiae tRNA ${ }^{\mathrm{Val}}$ (UAC) (Chen and Patton 1999). Putative tRNA: $\Psi 32$-synthase activity of mPus1p in yeast was verified in a strain carrying disruptions of both the PUS8 and PUS9 ORFs, encoding cytoplasmic and 


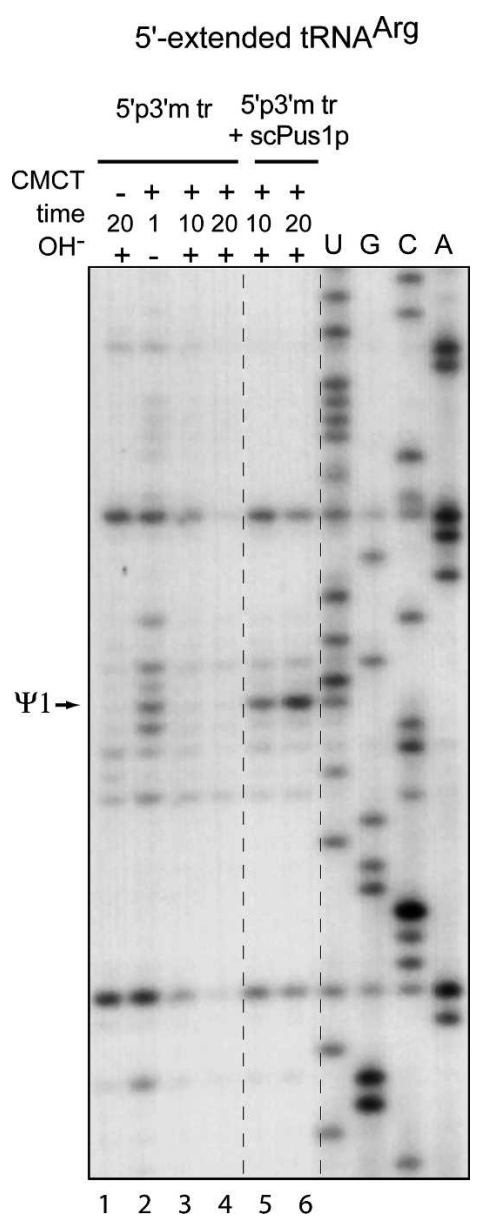

FIGURE 7. CMCT/RT mapping of $\Psi$ residues formed in a $5^{\prime}$ extended tRNA ${ }^{\mathrm{Arg}}$ transcript (5' $\left.3^{\prime} \mathrm{m}\right)$. An unlabeled 5' $5^{\prime} \mathrm{m}$ tRNA ${ }^{\mathrm{Arg}}$ transcript ( $5^{\prime} \mathrm{p} 3^{\prime} \mathrm{m}$ tr) was incubated with or without the recombinant $\mathrm{His}_{6}$-scPuslp (scPuslp) and analyzed by the CMCT/RT approach. RNAs were modified by CMCT, for 1,10 , and 20 min with $(+)$ or without $(-)$ subsequent alkaline treatment $\left(\mathrm{OH}^{-}\right)$. A control experiment was performed in the absence of CMCT treatment. Pseudouridylated positions were identified by extension of oligonucleotide O-tRNA ${ }^{\mathrm{Arg}}$ by reverse transcriptase. Lanes $U, G, C$, and $A$ correspond to the sequencing ladders obtained with the same oligonucleotide. The reverse transcription stop corresponding to residue $\Psi 1$ is indicated.

mitochondrial tRNA: $\Psi 32$-synthases, respectively ( $\Delta p u s 8$ $\Delta$ pus9 strain) (Behm-Ansmant et al. 2004). This strain was transformed with the p416GalS-mPUS1 plasmid and the CMCT/RT method was used to analyze the conversion of residue $\mathrm{U} 32$ into a pseudouridine in $\mathrm{tRNA}^{\mathrm{Gly}}(\mathrm{GCC})$ and
tRNA $^{\text {Val }}$ (CAC) (Fig. 1F, G). For both tRNAs, expression of mPus1p did not restore $\Psi 32$ formation at a detectable level (not shown).

Our data show that the scPuslp and mPuslp enzymes show several common tRNA: $\Psi$-synthase activities. In yeast cells, they both act at positions 27,34 , and 36 in tRNAs and the previously proposed difference of specificity of $s c \mathrm{Pus} 1 \mathrm{p}$ and mPuslp at position 32 in tRNAs is not confirmed by the present data. One of the positions (U27) modified by both enzymes is frequently modified in tRNAs. In contrast, in all the species studied until now, the presence of $\Psi 34$ and $\Psi 36$ residues was only detected in one tRNA (tRNA ${ }^{\mathrm{Ile}}(\mathrm{UAU})$ ) (Szweykowska-Kulinska et al. 1994). Although no clear experimental demonstration was obtained, the presence of these two $\Psi$ residues in the tRNA ${ }^{\text {Ile }}$ anticodon may participate in translational fidelity (Senger et al. 1997; Auffinger and Westhof 1998). Formation of residues 34 and 36 in yeast tRNA ${ }^{\text {Ile }}$ (UAU) occurs in the nucleus and was found to be strictly dependent on the presence of the intron (Szweykowska-Kulinska et al. 1994). Hence, our observation of an mPuslp activity at these two positions in yeast suggests a strong conservation of the complex maturation process of tRNA ${ }^{\mathrm{Ile}}(\mathrm{UAU})$. Unfortunately, knowledge on post-transcriptional modification in mouse tRNAs is rather limited (Sprinzl et al. 1998) and modifications in tRNA $^{\mathrm{Ile}}(\mathrm{UAU})$ were not studied in this species.

In yeast cells, in contrast to scPuslp, mPuslp was not found to act efficiently at position 28 in $\operatorname{tRNA}^{\operatorname{Trp}}(\mathrm{CCA})$. However, it was active at this position in vitro. As pseudouridylation at both positions 27 and 28 was found to be absent in the cytoplasmic tRNA ${ }^{\text {Ser }}$ (UGA) and mitochondrial tRNA ${ }^{\text {Lys }}(\mathrm{UUU})$ from patients suffering from MLASA (Patton et al. 2005), hPuslp is expected to act at position 28 in human cells. The low activity of mPuslp at position 28 in the yeast $\mathrm{tRNA}^{\operatorname{Tr}}$ (CCA) may be due to an unfavorable sequence of the anticodon stem-loop of this tRNA. Interestingly, previous experiments based on tRNA aminoacylation experiments suggested that residue $\Psi 28$ in the yeast $\mathrm{tRNA}^{\mathrm{Trp}}(\mathrm{CCA})$ is needed for stabilization of the anticodon stem, which is less stable compared to the corresponding stem-loop in bovine tRNA (Carnicelli et al. 2001). Therefore, one can imagine that in each of these species, the activity of Puslp at position 28 in tRNAs is sensitive to the sequence of the anticodon stems of the tRNAs that are modified. On the other hand, tRNA modification is

TABLE 1. Analysis of $\Psi 72$ formation in an in vitro transcribed yeast mitochondrial tRNA ${ }_{i}^{\mathrm{Met}}(\mathrm{CAU})$ after incubation either with extracts from wild-type, $\Delta$ pus 1, and $\Delta$ pus1 + p416GalS-mPUS1 yeast cells or with recombinant scPus1p and mPus1p

\begin{tabular}{ccccc}
\hline Wild-type strain & $\Delta$ pus1 strain & spus1 + p416GalS-mPUS1 strain & Recombinant scPus1p & Recombinant mPus1p \\
\hline 0.78 & 0.83 & 0.79 & $<0.01$ & $<0.01$
\end{tabular}

The tRNA ${ }^{\text {Met }}$ i transcripts were incubated with yeast extracts or recombinant proteins at $37^{\circ} \mathrm{C}$ for 60 min and the $\Psi$ content was analyzed by 2D-TLC after RNAse T2 digestion. Values are expressed in mole of $\Psi$ per mole of tRNA $( \pm 0.05)$. 
A

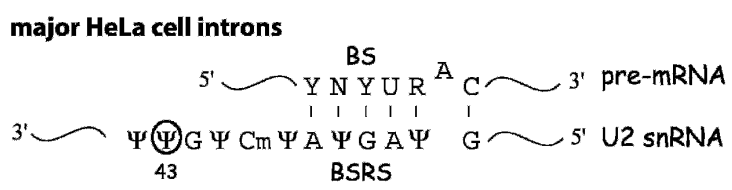

yeast S. cerevisiae introns

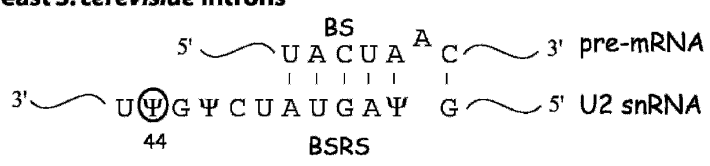

B

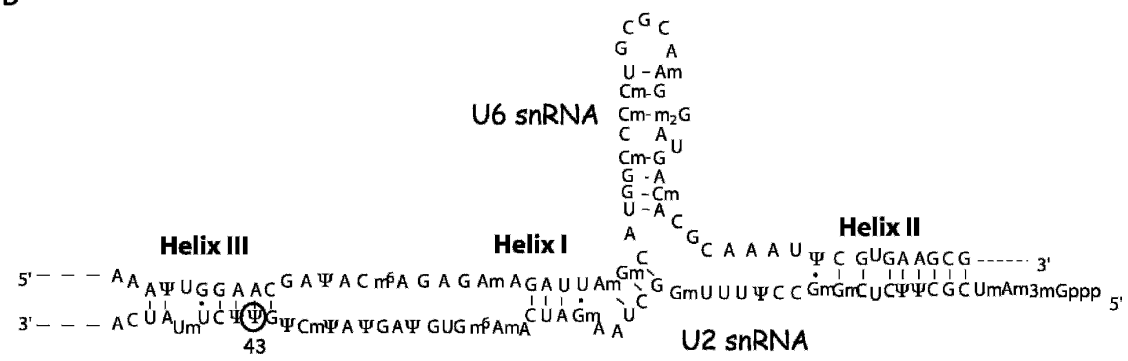

FIGURE 8. The $\Psi$ residue formed by Puslp in U2 snRNA is highly conserved and involved in a U2-U6 interaction. (A) The branch site (BS) consensus sequences of the major introns from vertebrates and the yeast introns are shown. The branch site recognition sequences (BSRS) of U2 snRNAs are indicated, as well as the modified nucleotides present in this U2 snRNA segment (for review, see Massenet et al. 1998). The philogenetically conserved $\Psi$ residue formed by Puslp in yeast is circled. $(B)$ The heterologous helices I, II, and III formed between the vertebrate U2 and U6 snRNAs are represented (Sun and Manley 1995; for review, see Madhani and Guthrie 1994). The post-transcriptional modifications are indicated, and the philogenetically conserved $\Psi$ residue formed by Puslp in yeast is circled (for review, see Massenet et al. 1998).

a complex multistep process that is accomplished by independently acting tRNA(RNA)-modification enzymes. In a few cases, the interdependence between tRNA modification at distinct positions has been demonstrated (Pintard et al. 2002). Thus, the observed difference between in vitro and in vivo activities of both enzymes may also be explained by the fact that, in a living cell, both enzymes act on partially modified pre-tRNA transcripts that are the real substrates of modification enzymes in vivo.

A second difference between scPuslp and mPuslp concerns position 26. Indeed, whereas scPuslp has an efficient in vivo tRNA: $\Psi 26$ activity toward the $\mathrm{tRNA}^{\text {Trp }}$ (CCA) (Motorin et al. 1998; present data), mPus1p was not found to modify this position efficiently. In connection with this observation, it should be pointed out that pseudouridylation at position 26 is not a frequent modification in vertebrate tRNAs. In fact, only one sequenced human tRNA (tRNA $^{\text {Met }}(\mathrm{CAU})$ ) has a $\Psi 26$ residue, while five others bear unmodified U at this position (Sprinzl et al. 1998).

The third difference detected between the two enzymes concerns the possible additional tRNA: $\Psi 30$-synthase activity of mPus1p. Obviously, other experiments, like a mPUS1 gene knockout, are required to confirm this activity in mouse. However, in agreement with our data, residue U30 is never pseudouridylated in yeast tRNAs, whereas a $\Psi 30$ residue is found in the mouse tRNA ${ }^{\text {Ile }}$ (AAU) (Fig. 4B; Shinriki et al. 1981; Sprinzl et al. 1998; the tRNA database: http://www.uni-bayreuth.de/departments/ biochemie/trna). Here again, this may be explained by divergence of the tRNA sequences in the course of evolution. In fact, the anticodon stems of the yeast tRNA $^{\text {Ile }}(\mathrm{UAU})$ and mouse tRNA ${ }^{\text {Ile }}(\mathrm{AAU})$ are more similar than are the anticodon stems of yeast and mouse tRNAs ${ }^{\text {Ile }}$ (UAU) (Fig. 4B).

Apart from the above-mentioned differences, we demonstrated that scPuslp and mPuslp both carry the yet unassigned yeast tRNA: $\Psi 1$-synthase activity and that these two proteins can act at this position in both precursor and mature tRNA molecules. The existence of a $\Psi 1$ residue in mouse tRNAs has not been reported yet, but, as already mentioned, the knowledge on post-transcriptional modifications in mouse tRNAs is rather limited (Sprinzl et al. 1998). According to the mouse genomic sequence, 22 tRNAs $\left(7\right.$ tRNA $^{\text {Asp }}, 4$ tRNA $^{\text {Gln }}$, 8 tRNA $^{\text {Glu }}, 1$ tRNA ${ }^{\text {Ser }}, 1$ tRNA ${ }^{\text {Tyr }}$, and 1 tRNA $^{\mathrm{Val}}$ ) are expected to have a U residue at position 1 , and post-transcriptional modifications were only studied for one of them, namely, tRNA ${ }^{\mathrm{Glu}}$ (CUC), which lacks the modification. Thus, there are still 21 tRNA candidates for a possible modification at position 1 .

Taken together, our data show a remarkable conservation of the RNA specificities of the Puslp enzymes, with a few differences that are likely explained by their coevolution with tRNA sequences.

\section{RNA substrate recognition by scPus1p and mPus1p}

Both yeast and mouse RNA: $\Psi$-synthases Pus1p are multisite-specific modification enzymes acting at multiple sites in tRNAs and are also able to modify pre-tRNAs and U2 snRNA. Based on the previous data on the scPuslp and mPuslp, it was generally thought that both enzymes recognize a relatively simple structural domain that consists of an RNA helix with an internal bulge bearing the target uridine. The present observation of a Puslp activity at position 1 in tRNA modifies the view of scPuslp and mPuslp specificities, since a simple RNA helix with an accessible uridine residue at its $5^{\prime}$ extremity is also a good substrate for both enzymes. Thus, both enzymes have very relaxed 
substrate specificities. Indeed, any accessible $U$ residue seems to be a substrate for Puslp modification, provided that an RNA helix is present in its vicinity. This relaxed substrate specificity does not exclude the possible existence of welldefined point identity determinants in the proximal RNA stem. Indeed, four yeast tRNAs bear U1 residue and thus are potential sc Pus1p substrates. However, only two out of these four tRNAs undergo in vivo conversion $U$ to $\Psi$ at position 1 .

\section{MATERIALS AND METHODS}

\section{Yeast strains}

The haploid S. cerevisiae BY4742 strain (denoted wild-type in this paper) and the haploid strain carrying a disruption of the PUS1 gene (pus $1 \Delta:: \mathrm{Kan}^{r}$, denoted $\Delta$ pus 1 ) have been obtained from the EUROSCARF collection (Germany). The S. cerevisiae BMA64derived strain with deletion of the PUS8 and PUS9 genes was previously described (Behm-Ansmant et al. 2004).

\section{mPus $1 p$ expression in yeast}

For mPuslp expression in yeast, the mPuslp ORF was recovered by digestion of plasmid pET16b-mPUS1 (described by Chen and Patton 1999) with the XbaI and XhoI endonucleases and cloned into yeast p416GalS expression plasmid (Mumberg et al. 1995). The junction regions and the entire insert sequence of the recombinant plasmid (p416-mPUS1) were sequenced. In this construction, expression of the mouse ORF is under the control of the inducible GalS promoter. To produce the D112A mPuslp variant, a point mutation (GAC $\rightarrow$ GCC; Asp $\rightarrow$ Ala) was introduced by PCR-mediated site-directed mutagenesis using the Quick Change Kit (Stratagene). By using the standard lithium acetate procedure (Adams et al. 1997), the haploid BY4742- $\Delta p u s 1$ and BMA64 $\Delta$ pus8- $\Delta p u s 9$ strains were transformed with the p416GalS plasmids containing either the wild-type or the mutated mPUS1 ORF. Transformed and untransformed strains were grown for $24 \mathrm{~h}$ in an Ura-Gal medium to induce expression of the transgene. Preparations of yeast cell-free S10 extracts for in vitro tRNA: $\Psi$-synthase activity assays and for preparation of total RNA extracts were done as described previously (Auxilien et al. 1996; Behm-Ansmant et al. 2003).

\section{Analysis of in vivo pseudouridylations by CMCT/RT mapping}

Total RNAs from the wild-type, $\Delta p u s 1, \Delta p u s 1+\mathrm{p} 416-\mathrm{mPUS1}$, $\Delta p u s 1+\mathrm{p} 416-\mathrm{mPUS1}(\mathrm{D} 112 \mathrm{~A}), \Delta p u s 8-\Delta p u s 9$ and $\Delta p u s 8-\Delta p u s 9+$ p416-mPUS1 yeast strains were prepared as described previously (Massenet et al. 1999). The $\Psi$ residues in tRNAs and U2 snRNA were analyzed by modification with 1-cyclohexyl-3-[2-morpholinoethyl] carbodiimide metho- $p$-toluenesulfonate (CMCT) followed by reverse transcription with specific primer (CMCT-RT approach) (Bakin and Ofengand 1993; Massenet et al. 1999). To test for tRNA: $\Psi$-synthase activities at positions 26,27 , and 28 in yeast tRNA ${ }^{\operatorname{Trp}}$ (CCA) (Keith et al. 1972) and 27, 34, and 36 in pretRNA $^{\mathrm{Ile}}(\mathrm{UAU})$, the oligonucleotides used as primers for reverse transcription were complementary to nucleotides 40-57 in $\mathrm{tRNA}^{\mathrm{Trp}}$ (CCA) (O-tRNA $\left.{ }^{\mathrm{Trp}}\right)$ and to the pre-tRNA ${ }^{\mathrm{Ile}}(\mathrm{UAU})$ intron
(O-pre-tRNA $\left.{ }^{\text {Ile }}\right)$, respectively. The tRNA: $\Psi 32$-synthase activity was tested on cytoplasmic tRNA ${ }^{\mathrm{Gly}}$ (GCC) and $\mathrm{tRNA}^{\mathrm{Val}}$ (CAC), using oligonucleotides complementary to positions 59-76. Sequences of tRNA substrates used in this study are presented in Figure 1.

\section{Expression and purification of the recombinant mPus1p and scPus1p}

ScPuslp and mPuslp were prepared as previously described (Simos et al. 1996; Chen and Patton 1999), except that the Escherichia coli strain BL21-CodonPlus(DE3)-RIL was used instead of the BL21 (DE3) pLysS strain.

\section{Production of tRNA transcripts}

Plasmid pT7U2 $2_{\mathrm{Sc}}$, kindly provided by P. Fabrizio (Max-PlanckInstitute of Biophysical Chemistry, Göttingen, Germany), was used for in vitro transcription of $S$. cerevisiae U2 snRNA. To produce in vitro transcribed yeast cytoplasmic tRNA ${ }^{\mathrm{Arg}}(\mathrm{ACG})$ and mitochondrial tRNA ${ }^{\mathrm{Met}} \mathrm{i}(\mathrm{CAU})$, the coding sequences were amplified by polymerase chain reaction (PCR) using genomic DNA from the S. cerevisiae BMA64 strain. The sense oligonucleotide was designed in order to introduce a T7 RNA polymerase promoter. DNA templates for production of $5^{\prime}-$ and $3^{\prime}$-extended tRNA ${ }^{A r g}$ transcripts were prepared by PCR amplification using oligonucleotides containing corresponding extensions. The amplified fragments were inserted at the SmaI restriction site of plasmid pUC18. The pTFM-Val plasmid used for in vitro transcription of cytoplasmic tRNA ${ }^{\text {Val }}(\mathrm{UAC})$ was kindly provided by C. Florentz (IBMC, Strasbourg, France). Prior to in vitro transcription, the pUC18tRNA $^{\text {Arg }}$, pUC19-tRNA ${ }^{\text {Met }}$, and pTFM-Val plasmids were all cleaved with the BstNI nuclease. In vitro T7 RNA polymerase transcription with or without incorporation of the appropriate $\left[\alpha-{ }^{32} \mathrm{P}\right] \mathrm{NTP}$ and $\mathrm{pu}-$ rification of the resulting RNA transcripts by electrophoresis on denaturing gel were performed as previously described (Jiang et al. 1997).

\section{In vitro RNA: $\Psi$-synthase activity assays}

The tRNA: $\Psi$-synthase activities of recombinant $\mathrm{His}_{6}$-mPuslp, $\mathrm{His}_{6}{ }^{-}$ scPuslp, and of total cellular extracts were tested by incubation of the purified proteins or the S10 extracts with total RNA fractions extracted from $\Delta p u s 1$ strain or with in vitro produced yeast tRNAs and U2 snRNA transcripts. Total RNA $(10 \mu \mathrm{g})$ or tRNA transcript (50-100 fmol) were incubated for $2 \mathrm{~h}$ with $\sim 0.2 \mu \mathrm{g}$ of the recombinant protein or $10 \mu \mathrm{L}$ of $\mathrm{S} 10$ cellular extract (final concentration of about $0.5-1.0 \mathrm{mg}$ of total protein $/ \mathrm{mL}$ ), in the following buffer: $100 \mathrm{mM}$ Tris- $\mathrm{HCl}$ ( $\mathrm{pH} 8.0$ ), $100 \mathrm{mM}$ ammonium acetate, $5 \mathrm{mM}$ $\mathrm{MgCl}_{2}, 2 \mathrm{mM}$ DTT, $0.1 \mathrm{mM}$ EDTA. After incubation, the modified RNAs were phenol extracted, precipitated by ethanol, and analyzed by either the CMCT/RT method or the nearest neighbor approach.

To study the tRNA: $\Psi$-synthase activities at position 1 in yeast cytoplasmic tRNA ${ }^{\mathrm{Arg}}(\mathrm{ACG})$ and its precursors, the in vitro transcribed RNAs were labeled with $\left[\alpha-{ }^{32} \mathrm{P}\right] \mathrm{UTP}$. For analysis of the tRNA: $\Psi 72$-synthase activity by the nearest neighbor approach, the yeast mitochondrial tRNA ${ }_{i}^{\text {Met }}(\mathrm{CAU})$ was labeled with $\left[\alpha-{ }^{32} \mathrm{P}\right]$ ATP. After modification, the tRNA transcripts were totally digested with RNase T2 and the produced 3' NMPs were fractionated by two-dimensional thin layer chromatography (2D-TLC), as previously described (Jiang et al. 1997). 


\section{Analysis of $\Psi 1$ residue formation by 5 ' labeling of RNAs}

The presence of $\Psi 1$ residues in in vivo or in vitro modified tRNAs was analyzed by complete digestion of $5^{\prime}$-labeled tRNA fractions with nuclease $\mathrm{P} 1$, followed by $2 \mathrm{D}$-TLC analysis of the resulting 5 -NMPs. Specific labeling of 5'-terminal nucleotides was achieved by dephosphorylation of the total tRNA fraction $(\sim 20 \mu \mathrm{g})$ with alkaline phosphatase $(1 \mathrm{U} / \mu \mathrm{g})$ and subsequent $5^{\prime}$ labeling with $\left[\gamma^{-}{ }^{32} \mathrm{P}\right]$ ATP and T4 polynucleotide kinase $(2 \mathrm{U})$ for $45 \mathrm{~min}$ at $37^{\circ} \mathrm{C}$. To verify that the $\Psi$ MP detected in the $5^{\prime}$-extended tRNA ${ }^{\mathrm{Arg}}(\mathrm{ACG})$ corresponded to modification at position 1 , the modified transcript was analyzed by reverse transcription using an oligonucleotide complementary to bases 55-76 (O-tRNA $\left.{ }^{\text {Arg }}\right)$.

Purification of a highly enriched fraction of yeast tRNAs was accomplished by high-performance anion-exchange chromatography on a MonoQ HR5/5 column (Amersham Biosciences) followed by PAGE on denaturing urea gels. The region of the gel corresponding to tRNAs was excised and the RNAs were eluted and precipitated by ethanol.

\section{ACKNOWLEDGMENTS}

We thank C. Florentz and R. Giegé (CNRS, Strasbourg, France) for helpful discussions and for providing plasmid containing the yeast tRNA ${ }^{\mathrm{Val}}$ coding region, P. Fabrizio (Max-Planck-Institute of Biophysical Chemistry, Göttingen, Germany), for providing plasmid pT7U2, and J. Ugolini for technical assistance. This work was supported by laboratory funds from the CNRS and the "Ministère de la jeunesse, de l'éducation nationale et de la recherche" and a Research and Productive Scholarship Grant from the University of South Carolina to J.R.P. I. Behm-Ansmant was a pre-doctoral fellow from the "Ministère de la jeunesse, de l'éducation nationale et de la recherche."

Received March 30, 2006; accepted May 18, 2006.

\section{REFERENCES}

Adams, A., Gottschling, D.E., Kaiser, C.A., and Stearns, T. 1997. Methods in yeast genetics.. Cold Spring Harbor Laboratory Press, Cold Spring Harbor, NY.

Ansmant, I. and Motorin, I. 2001. Identification of RNA modification enzymes using sequence homology. Mol. Biol. (Mosk.) 35: 248-267.

Auffinger, P. and Westhof, E. 1998. Effects of pseudouridylation on tRNA hydration and dynamics: A theoretical approach. In The modification and editing of RNA (eds. H. Grosjean and R. Benne), pp. 103-112. ASM Press, Washington, DC.

Auxilien, S., Crain, P.F., Trewyn, R.W., and Grosjean, H. 1996. Mechanism, specificity and general properties of the yeast enzyme catalysing the formation of inosine 34 in the anticodon of transfer RNA. J. Mol. Biol. 262: 437-458.

Bakin, A. and Ofengand, J. 1993. Four newly located pseudouridylate residues in Escherichia coli $23 \mathrm{~S}$ ribosomal RNA are all at the peptidyltransferase center-Analysis by the application of a new sequencing technique. Biochemistry 32: 9754-9762.

Behm-Ansmant, I., Urban, A., Ma, X., Yu, Y.T., Motorin, Y., and Branlant, C. 2003. The Saccharomyces cerevisiae U2 snRNA:pseudouridine-synthase Pus7p is a novel multisite-multisubstrate RNA:Psi-synthase also acting on tRNAs. RNA 9: 1371-1382.

Behm-Ansmant, I., Grosjean, H., Massenet, S., Motorin, Y., and Branlant, C. 2004. Pseudouridylation at position 32 of mitochon- drial and cytoplasmic tRNAs requires two distinct enzymes in Saccharomyces cerevisiae. J. Biol. Chem. 279: 52998-53006.

Bjork, G.R., Ericson, J.U., Gustafsson, C.E., Hagervall, T.G., Jonsson, Y.H., and Wikstrom, P.M. 1987. Transfer RNA modification. Annu. Rev. Biochem. 56: 263-287.

Bykhovskaya, Y., Casas, K., Mengesha, E., Inbal, A., and FischelGhodsian, N. 2004. Missense mutation in pseudouridine synthase 1 (PUS1) causes mitochondrial myopathy and sideroblastic anemia (MLASA). Am. J. Hum. Genet. 74: 1303-1308.

Canaday, J., Dirheimer, G., and Martin, R.P. 1980. Yeast mitochondrial methionine initiator tRNA: Characterization and nucleotide sequence. Nucleic Acids Res. 8: 1445-1457.

Carnicelli, D., Brigotti, M., Rizzi, S., Keith, G., Montanaro, L., and Sperti, S. 2001. Nucleotides U28-A42 and A37 in unmodified yeast tRNA(Trp) as negative identity elements for bovine tryptophanyltRNA synthetase. FEBS Lett. 492: 238-241.

Chen, J. and Patton, J.R. 1999. Cloning and characterization of a mammalian pseudouridine synthase. RNA 5: 409-419.

. 2000. Pseudouridine synthase 3 from mouse modifies the anticodon loop of tRNA. Biochemistry 39: 12723-12730.

Darzacq, X., Jady, B.E., Verheggen, C., Kiss, A.M., Bertrand, E., and Kiss, T. 2002. Cajal body-specific small nuclear RNAs: A novel class of 2'-O- methylation and pseudouridylation guide RNAs. EMBO J. 21: 2746-2756.

Ganot, P., Jady, B.E., Bortolin, M.L., Darzacq, X., and Kiss, T. 1999. Nucleolar factors direct the 2'-O-ribose methylation and pseudouridylation of U6 spliceosomal RNA. Mol. Cell. Biol. 19: 69066917.

Gozani, O., Feld, R., and Reed, R. 1996. Evidence that sequenceindependent binding of highly conserved U2 snRNP proteins upstream of the branch site is required for assembly of spliceosomal complex A. Genes \& Dev. 10: 233-243.

Gustafsson, C., Reid, R., Greene, P.J., and Santi, D.V. 1996. Identification of new RNA modifying enzymes by iterative genome search using known modifying enzymes as probes. Nucleic Acids Res. 24: 3756-3762.

Hellmuth, K., Grosjean, H., Motorin, Y., Deinert, K., Hurt, E., and Simos, G. 2000. Cloning and characterization of the Schizosaccharomyces pombe tRNA:pseudouridine synthase Pus1p. Nucleic Acids Res. 28: 4604-4610.

Jady, B.E. and Kiss, T. 2001. A small nucleolar guide RNA functions both in 2'-O-ribose methylation and pseudouridylation of the U5 spliceosomal RNA. EMBO J. 20: 541-551.

Jiang, H.-Q., Motorin, Y.A., Jin, Y.-X., and Grosjean, H. 1997. Pleiotropic effects of intron removal on base modifications pattern of yeast tRNA ${ }^{\text {Phe }}$ : An in vitro study. Nucleic Acids Res. 25: 26942701.

Kammen, H.O., Marvel, C.C., Hardy, L., and Penhoet, E.E. 1988. Purification, structure, and properties of Escherichia coli tRNA pseudouridine synthase I. J. Biol. Chem. 263: 2255-2263.

Kaya, Y. and Ofengand, J. 2003. A novel unanticipated type of pseudouridine synthase with homologs in bacteria, archaea, and eukarya. RNA 9: 711-721.

Keith, G. 1995. Mobilities of modified ribonucleotides on twodimensional cellulose thin-layer chromatography. Biochimie 77: 142-144.

Keith, G., Roy, A., Ebel, J.P., and Dirheimer, G. 1972. The primary structure of $\mathrm{tRNA}^{\mathrm{Trp}}$ from brewer's yeast. I. Complete digestion with pancreatic ribonuclease and T 1 ribonuclease. Biochimie 54: 1405-1426.

Kiss, A.M., Jady, B.E., Bertrand, E., and Kiss, T. 2004. Human box H/ ACA pseudouridylation guide RNA machinery. Mol. Cell. Biol. 24: 5797-5807.

Koonin, E.V. 1996. Pseudouridine synthases: Four families of enzymes containing a putative uridine-binding motif also conserved in dUTPases and dCTP deaminases. Nucleic Acids Res. 24: 24112415.

Kufel, J. and Tollervey, D. 2003. $3^{\prime}$-processing of yeast tRNA ${ }^{\text {Trp }}$ precedes 5'-processing. RNA 9: 202-208. 
Ma, X., Zhao, X., and Yu, Y.T. 2003. Pseudouridylation $(\psi)$ of U2 snRNA in $S$. cerevisiae is catalyzed by an RNA-independent mechanism. EMBO J. 22: 1889-1897.

Ma, X., Yang, C., Alexandrov, A., Grayhack, E.J., Behm-Ansmant, I., and Yu, Y.T. 2005. Pseudouridylation of yeast U2 snRNA is catalyzed by either an RNA-guided or RNA-independent mechanism. EMBO J. 24: 2403-2413.

Madhani, H.D. and Guthrie, C. 1994. Dynamic RNA-RNA interactions in the spliceosome. Annu. Rev. Genet. 28: 1-26.

Madison, J.T. and Boguslawski, S.J. 1974. Partial digestion of a yeast lysine transfer ribonucleic acid and reconstruction of the nucleotide sequence. Biochemistry 13: 524-527.

Massenet, S., Mougin, A., and Branlant, C. 1998. Posttranscriptional modifications in the $\mathrm{U}$ small nuclear RNAs. In The modification and editing of RNA (eds. H. Grosjean and R. Benne), pp. 201-228. ASM Press, Washington, DC.

Massenet, S., Motorin, Y., Lafontaine, D.L., Hurt, E.C., Grosjean, H., and Branlant, C. 1999. Pseudouridine mapping in the Saccharomyces cerevisiae spliceosomal U small nuclear RNAs (snRNAs) reveals that pseudouridine synthase puslp exhibits a dual substrate specificity for U2 snRNA and tRNA. Mol. Cell. Biol. 19: 21422154.

Motorin, Y., Keith, G., Simon, C., Foiret, D., Simos, G., Hurt, E., and Grosjean, H. 1998. The yeast tRNA:pseudouridine synthase Pus1p displays a multisite substrate specificity. RNA 4: 856-869.

Mumberg, D., Muller, R., and Funk, M. 1995. Yeast vectors for the controlled expression of heterologous proteins in different genetic backgrounds. Gene 156: 119-122.

Ofengand, J. 2002. Ribosomal RNA pseudouridines and pseudouridine synthases. FEBS Lett. 514: 17-25.

Ofengand, J. and Fournier, M.J. 1998. The pseudouridine residues of rRNA: Number, location, biosynthesis and function. In The modification and editing of RNA (eds. H. Grosjean and R. Benne), pp. 229-254. ASM Press, Washington, DC.

Patton, J.R. and Padgett, R.W. 2003. Caenorhabditis elegans pseudouridine synthase 1 activity in vivo: tRNA is a substrate, but not U2 small nuclear RNA. Biochem. J. 372: 595-602.

Patton, J.R., Bykhovskaya, Y., Mengesha, E., Bertolotto, C., and Fischel-Ghodsian, N. 2005. Mitochondrial myopathy and sideroblastic anemia (MLASA): Missense mutation in the pseudouridine synthase 1 (PUS1) gene is associated with the loss of tRNA pseudouridylation. J. Biol. Chem. 280: 19823-19828.

Pintard, L., Lecointe, F., Bujnicki, J.M., Bonnerot, C., Grosjean, H., and Lapeyre, B. 2002. Trm7p catalyses the formation of two 2'-Omethylriboses in yeast tRNA anticodon loop. EMBO J. 21: 18111820.

Schon, A. 1999. Ribonuclease P: The diversity of a ubiquitous RNA processing enzyme. FEMS Microbiol. Rev. 23: 391-406.

Senger, B., Auxilien, S., Englisch, U., Cramer, F., and Fasiolo, F. 1997. The modified wobble base inosine in yeast tRNA ${ }^{\text {Ile }}$ is a positive determinant for aminoacylation by isoleucyl-tRNA synthetase. Biochemistry 36: 8269-8275.
Shinriki, N., Ishizaki, K., Ikehata, A., Miura, K., Ueda, T., Kato, N., and Harada, F. 1981. Mode of degradation of tRNAs with ozone. Nucleic Acids Symp. Ser. 10: 211-214.

Simos, G., Tekotte, H., Grosjean, H., Segref, A., Sharma, K., Tollervey, D., and Hurt, E.C. 1996. Nuclear pore proteins are involved in the biogenesis of functional tRNA. EMBO J. 15: 22702284.

Sprinzl, S., Horn, C., Brown, M., Ioudovitch, A., and Steinberg, S. 1998. Compilation of tRNA sequences and sequences of tRNA genes. Nucleic Acids Res. 26: 148-153.

Sun, J.S. and Manley, J.L. 1995. A novel U2-U6 snRNA structure is necessary for mammalian mRNA splicing. Genes \& Dev. 9: 843854.

Szweykowska-Kulinska, Z., Senger, B., Keith, G., Fasiolo, F., and Grosjean, H. 1994. Intron-dependent formation of pseudouridines in the anticodon of Saccharomyces cerevisiae minor tRNA ${ }^{\text {Ile }}$. EMBO J. 13: 4636-4644.

Vitali, P., Royo, H., Seitz, H., Bachellerie, J.P., Huttenhofer, A., and Cavaille, J. 2003. Identification of 13 novel human modification guide RNAs. Nucleic Acids Res. 31: 6543-6551.

Weissenbach, J., Martin, R., and Dirheimer, G. 1975. The primary structure of $\mathrm{tRNA}_{\mathrm{II}}^{\mathrm{Arg}}$ from brewers' yeast. 2. Partial digestion with ribonuclease $\mathrm{T} 1$ and derivation of the complete sequence. Eur. J. Biochem. 56: 527-532.

Wells, S.E. and Ares Jr., M. 1994. Interactions between highly conserved U2 small nuclear RNA structures and Prp5p, Prp9p, Prp11p, and Prp21p proteins are required to ensure integrity of the U2 small nuclear ribonucleoprotein in Saccharomyces cerevisiae. Mol. Cell. Biol. 14: 6337-6349.

Wells, S.E., Neville, M., Haynes, M., Wang, J., Igel, H., and Ares Jr., M. 1996. CUS1, a suppressor of cold-sensitive U2 snRNA mutations, is a novel yeast splicing factor homologous to human SAP 145. Genes \& Dev. 10: 220-232.

Yan, D., Perriman, R., Igel, H., Howe, K.J., Neville, M., and Ares Jr., M. 1998. CUS2, a yeast homolog of human Tat-SF1, rescues function of misfolded U2 through an unusual RNA recognition motif. Mol. Cell. Biol. 18: 5000-5009.

Zeharia, A., Fischel-Ghodsian, N., Casas, K., Bykhocskaya, Y., Tamari, H., Lev, D., Mimouni, M., and Lerman-Sagie, T. 2005. Mitochondrial myopathy, sideroblastic anemia, and lactic acidosis: An autosomal recessive syndrome in Persian Jews caused by a mutation in the PUS1 gene. J. Child Neurol. 20: 449-452.

Zhao, X., Li, Z.H., Terns, R.M., Terns, M.P., and Yu, Y.T. 2002. An H/ACA guide RNA directs U2 pseudouridylation at two different sites in the branchpoint recognition region in Xenopus oocytes. RNA 8: $1515-1525$.

Zhao, X., Patton, J.R., Davis, S.L., Florence, B., Ames, S.J., and Spanjaard, R.A. 2004. Regulation of nuclear receptor activity by a pseudouridine synthase through posttranscriptional modification of steroid receptor RNA activator. Mol. Cell 15: 549-558. 

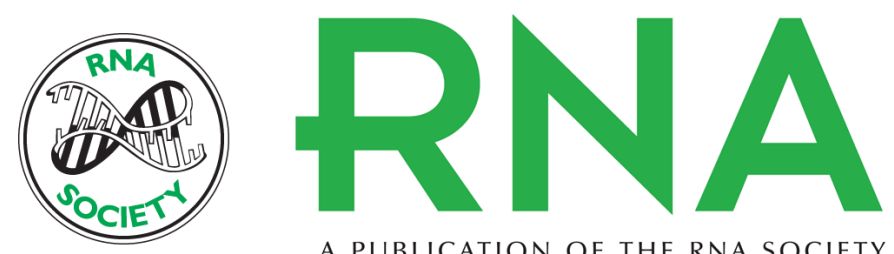

A PUBLICATION OF THE RNA SOCIETY

\section{A previously unidentified activity of yeast and mouse RNA:pseudouridine synthases 1 (Pus1p) on tRNAs}

Isabelle Behm-Ansmant, Séverine Massenet, FranÇoise Immel, et al.

RNA 2006 12: 1583-1593

References This article cites 51 articles, 21 of which can be accessed free at:

http://rnajournal.cshlp.org/content/12/8/1583.full.html\#ref-list-1

License

Email Alerting Receive free email alerts when new articles cite this article - sign up in the box at the Service top right corner of the article or click here.

To subscribe to RNA go to:

http://rnajournal.cshlp.org/subscriptions 